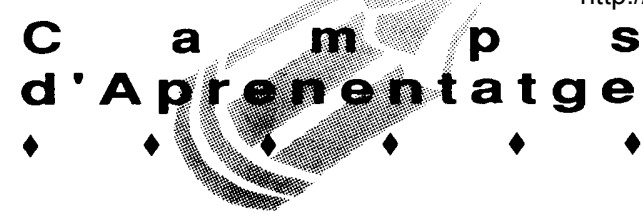

\title{
EL CAMP D'APRENENTATGE "CIUTAT DE TARRAGONA"
}

Joan Aluja I Miro. Camp d'Aprenentatge de Tarragona

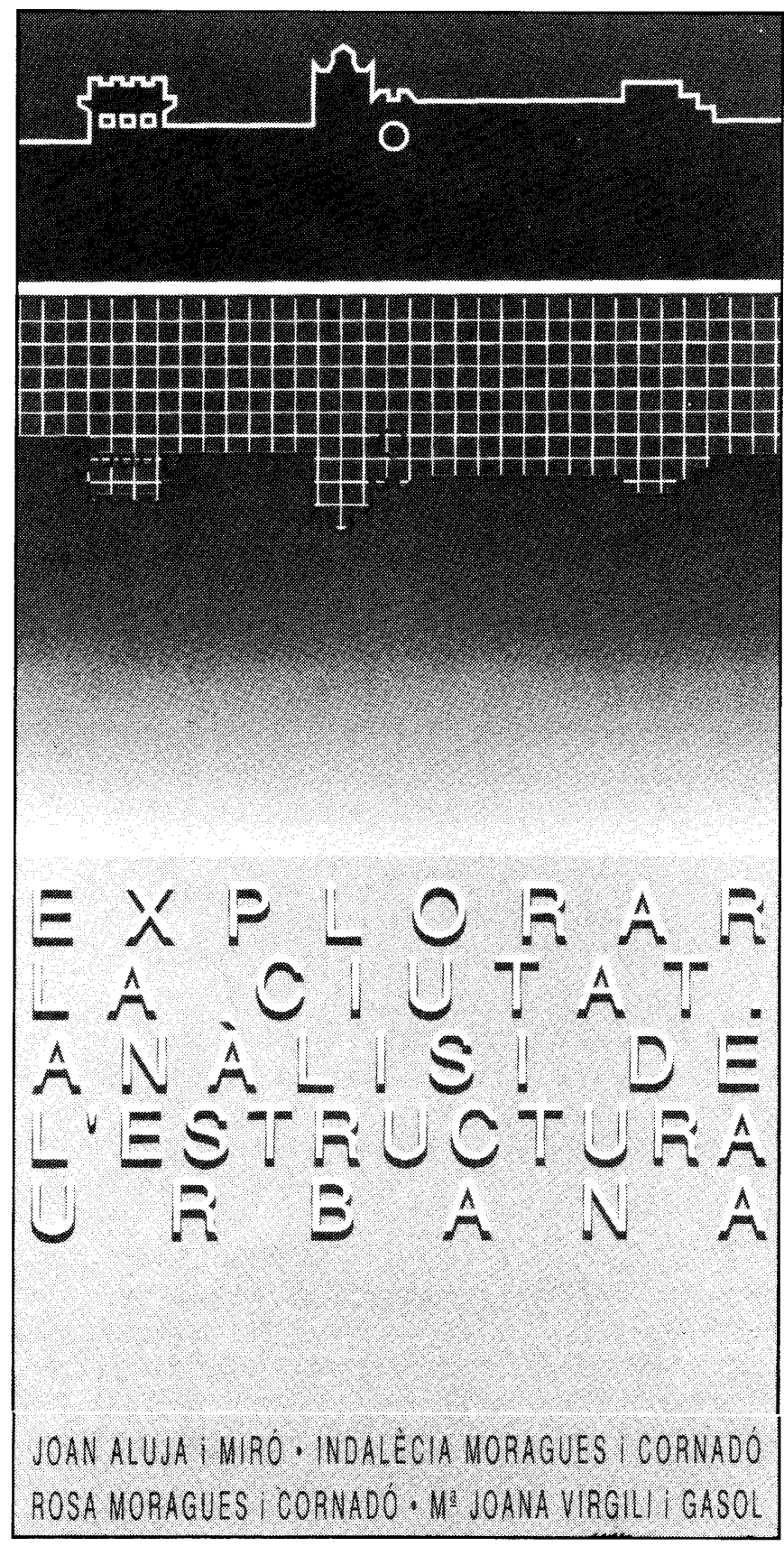

Treballar el medi des de l'escola ha estat una reivindicació antiga i estesa. Després de molts anys de plantejaments $i$ experimentacions, el fet de veure-ho escrit fins $i$ tot en el nou disseny curricular no deix de ser una satisfacció.

El problema que segueix és el de definir què i quin? és el medi dels nostres alumnes. Resulta difícil circumscriure el medi al seu entorn físic més proper, quan cada cop reben més informació d'esdeveniments iformes de vida d'altres parts del planeta. Així, ara podem fer-nos una pregunta: segueix essent vàlid parlar de l'estudi del medi? La resposta del Camp d'Aprenentatge és que sí. Cal, però, esbrinar quin és el medi dels nostres alumnes.

Es pot considerar que tothom té coneixements $\mathrm{i}$ vivències de tres tipus de medi:

* El medi viscut. És el més proper físicament a l'alumne, és el lloc on viu.

*El medi visitat. És on, pel motiu que sigui, l'alumne es desplaça amb la intenció més o menys directa de conèixer-lo.

*El medi conegut. És el que es coneix a través del mitjans de comunicació àudio-visual.

I tots ells són importants.

\section{Objectius}

El Camp d'Aprenentatge de Tarragona vol oferir als alumnes que participen en les seves activitats didàctiques d'estudi de la ciutat de Tarragona en les modalitats de medi viscut - els que viuen a Tarragona i al seu entorn-i de medi visitat per als que viuen a zones allunyades de Tarragona.

Els Camps d'Aprenentatge basem el nostre treball amb la idea que expressa aquest lema: APRENDRE DE L'ENTORN, que interpretem com el fet d'extreure del nostre entorn ciutadà tots els aspectes que són susceptibles, en un sentit ampli, de ser usats com a elements educatius en una pràctica docent integrada dins els programes escolars de cada centre. També és finalitat del Camp d'Aprenentatge col.laborar en la formació del professorat per la via de la utilització de les nostres propostes didàctiques, les quals poden convertir-se en 


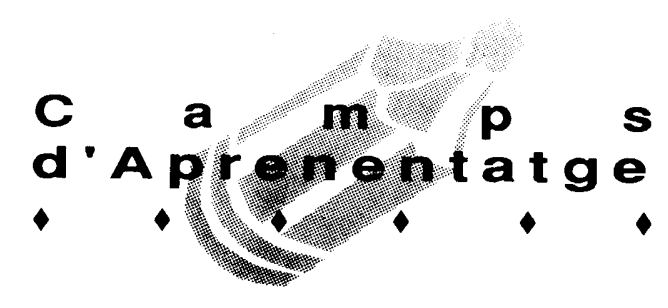

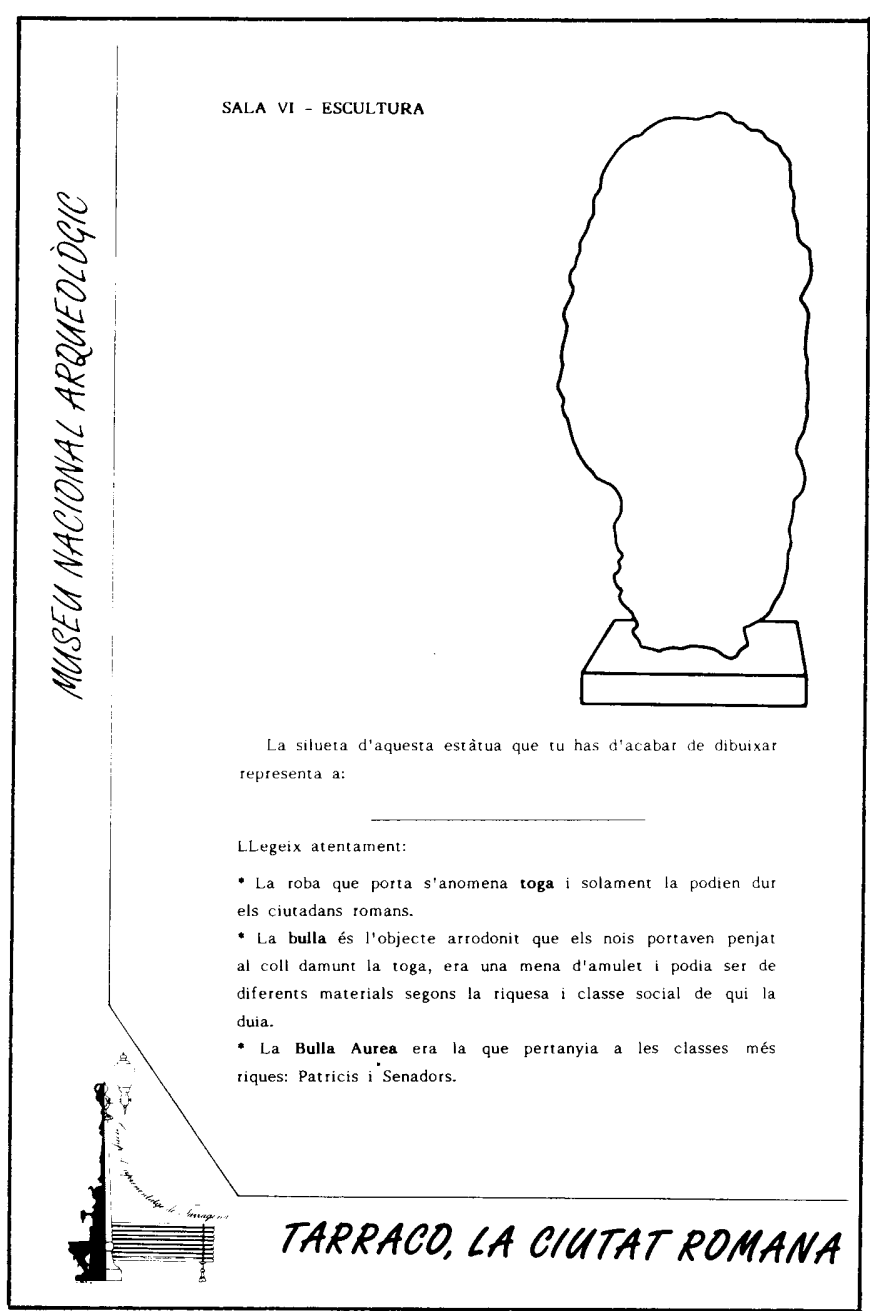

models o pautes de cara a l'elaboració de propostes $i$ materials d'estudi d'altres medis. És en aquest sentit que s'ofereix als centres que ho sol.liciten estades d'un sol dia (les de l'entorn més proper) o de cinc dies, de dilluns a divendres, (les zones més allunyades).

\section{Propostes de treball}

Les propostes didàctiques que actualment podem oferir als centres que ho sol.licitin són:

Tarraco, la ciutat romana. El coneixement de la ciutat a l'època romana pretén explicar les formes de vida en aquest moment històric a partir de les restes de Tarraco que actualment es conserven a la ciutat.

La vi.la romana dels "Munts". Un acostament al que era l'ocupació del territori en època romana, el "territorium" de Tarraco, basant-nos en la visita a les restes de la vi.la dels "Munts".

Activitats entorn de la ciutat a l'època medieval, que es concreten en les propostes didàctiques: "Joc de ciutat de la Tarragona Medieval". Un recorregut autònom per la part alta de la ciutat on, sota l'estructura d'un joc de pistes, els alumnes descobreixen els elements de diverses èpoques que constitueixen actualment aquesta zona de Tarragona i, "La catedral de Tarragona" (dos nivells de treball). Un treball que permet conèixer els elements arquitectònics i iconogràfics de la Seu tarragonina.

Treballs de geografia urbana. Són les propostes didàctiques: "Explorar la ciutat. Anàlisi de l'estructura urbana". Proposta de treball que per mitjà d'uns indicadors vol possibilitar als alumnes el coneixement global de la ciutat. "Itineraris urbans". Un recorregut per diverses zones de la ciutat per copsar-ne les similituts i diferències, i una pràctica d'educació vial en els seus desplaçaments per la ciutat.

"La indústria química del Camp de Tarragona. Itinerari de Localització Industrial". Un recorregut per les zones industrials de Tarragona (visitant una indústria petroquímica) i l'impacte que sobre el poblament de la ciutat $i$ el seu entorn ha suposat el desenvolupament industrial dels darrers trenta anys.

"Les activitats entorn delportide la pesca". Proposta didàctica que vol mostrar globalment les activitats que s'hi realitzen i la seva connexió amb la ciutat.

També cal fer referència a la utilització del Camp d'Aprenentatge com un centre de recursos específic de materials d'estudi del medi $i$ a partir del medi. Això significa posar a l'abast de l'ensenyant interessat el material de què disposa el Camp d'Aprenentatge sobre el tema. 